\title{
The influence of a soil compaction process on subsequent soil tillage processes. A new research method
}

\author{
A. J. Koolen \\ Tillage Laboratory, Agricultural University, Diedenweg 20, Wageningen, \\ the Netherlands
}

Accepted: 21 December 1977

Key words: soil tillage processes, soil physical properties, model treatments

\section{Summary}

The influence of a soil tillage process on subsequent tillage processes was studied by laboratory experiments on small soil samples. Suction curves as well as the relation between moisture content and strength properties depend on moisture content at precompaction.

The described method allows the testing of many variables at relatively low costs.

\section{Introduction}

At the start of the growing season, field operations to prepare a seed-bed usually compact the soil under the seed-bed. During subsequent field operations and harvesting of the crop, the soil may again be compacted. After harvesting, energy is applied to loosen the soil. To make cropping as optimal as possible (i.e., to reach maximum profits), it is necessary to know how these three sets of operations influence each other. An important question, for instance, is how much influence soil moisture content at seed-bed preparation has on the degree of a possible further compaction during subsequent field operations and harvesting, and on the energy needed to loosen the soil after harvesting.

This question could be investigated by using experimental fields. This approach has the advantage that the results can easily be transferred into practice. The costs, however, are rather high. Attempts to answer this question could also be made by subjecting small soil samples to 'model' cultivations in the laboratory; in this case a series of loose soil samples of different moisture contents is compacted by a model compaction process that should simulate the compaction process involved in seed-bed preparation. Subsequently, the moisture contents of these samples are allowed to change according to practical conditions. Measurements of either further compaction due to a second model compaction process, 
or how much energy is needed to break (loosen) them by a model cultivation, can then be made on these samples.

Such a laboratory method makes it possible to simulate many different situations at relatively low costs. However, it has not yet been exactly established which model compactions or model cultivations adequately simulate practical conditions, and how quantities measured on model cultivations can be 'translated' into practice. This article presents such a laboratory experiment.

\section{Model treatments}

\section{Compaction at seed-bed preparation}

This compaction is mainly caused by tractors used in the preparation. The compaction process under a tyre can be simulated by the uniaxial compaction test (see Fig. 1a). In this test a soil sample in a cylinder is gradually compacted under a piston. When mean stress under the piston $\left(\sigma_{1}\right)$ has reached a value representative of the compacting stress in the soil under a tractor tyre, the sample is unloaded. The maximum value of $\sigma_{1}$ in the uniaxial compaction test, which will produce as much compaction as is present under a tyre, has still not been exactly established, but this $\sigma_{1}$ is certainly higher than the mean normal stress in the contact surface between the tyre and the soil (Koolen, 1976a). Mean normal stress in the contact surface $=$ tyre inflation pressure +10 to $15 \%$ (Anon., 1973). In the laboratory experiment under consideration a value of 4 bar $\left(4.10^{5}\right.$ $\mathrm{Pa}$ ) was chosen for the maximal $\sigma_{1}$. This pressure was applied to silty clay loam samples at moisture contents ranging from lower than the hygroscopic point to higher than field capacity. To achieve these moisture contents cylinders filled with 2-3 $\mathrm{mm}$ aggregates being slightly drier than the hygroscopic point were saturated and then dried.
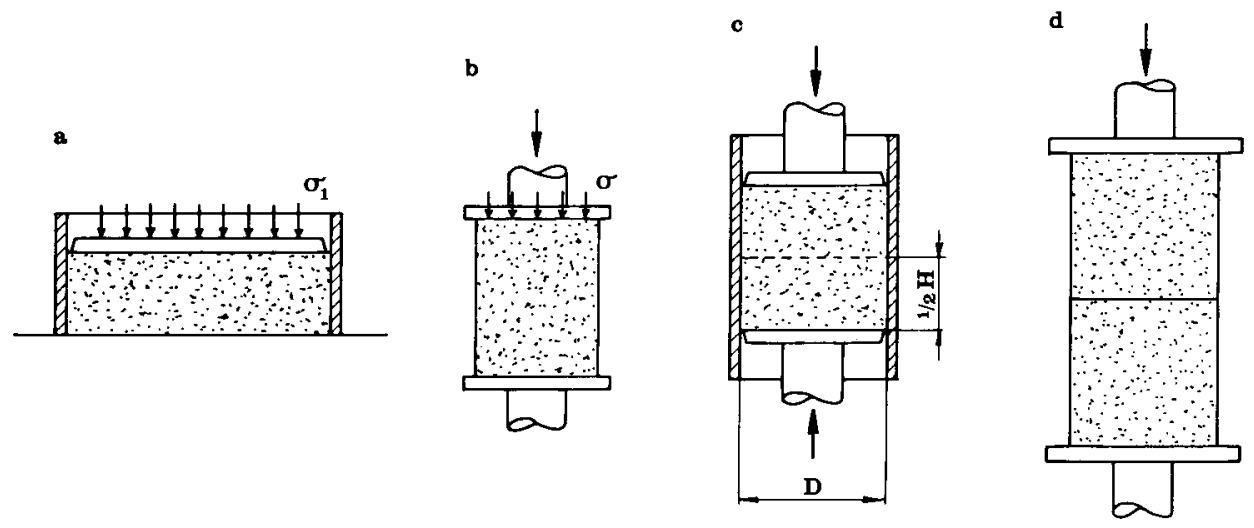

Fig. 1. Standard uniaxial compaction test (a) and standard unconfined compression test (b). Modified tests (c and d). 


\section{Changes in moisture content after seed-bed preparation}

The samples obtained in this way (pre-compacted samples) can stay in the cylinders while undergoing the changes in moisture content necessary for simulating practical conditions. In the laboratory experiments the pre-compacted samples were saturated and then dried to salient soil moisture suction values. This was accompanied by swelling and shrinking.

\section{Further compaction during subsequent field operations and harvesting}

Simulation of a further compaction during subsequent field operations and harvesting can also take place in these cylinders, by performing a second compaction with a piston that moves downwards at a linear speed. By measuring mean pressure on the piston $\left(\sigma_{1}\right)$ and soil porosity $(P)$ continuously during the test, a $\sigma_{1}-P$ relationship describing the behaviour in further compaction can be determined for pre-compacted samples. In the laboratory experiment further compaction took place up to $\sigma_{1}=5$ bar, at a pre-adjusted soil moisture suction for which the sensitivity of the used soil to a 5 bar compactive stress was expected to be highest. On the basis of previous experiments, $\mathrm{pF}=2.7$ was chosen for this. Prior to further compaction there was occasionally some space between the soil samples and the cylinder walls due to shrinkage during changing of the moisture contents. This was not considered as a hindrance, because vertical shrinkage cracks also occur under practical conditions. During further compaction, this space in the cylinders never led to peaks in the compactive stress-sinkage relationships. (A peak would develop if the sample failed in unconfined compression before full contact between sample wall and cylinder wall was recovered in the course of the test.)

\section{Energy needed for loosening}

Loosening after harvesting can be simulated by removing the cylinders from the samples after the necessary moisture changes and subjecting the samples to the unconfined compression test. (In this test a soil sample is made to fail between two pressing plates; Fig. 1b.) At the moment of failure, the prevailing failure stress $\left(\sigma_{\max }\right)$ and the sample shortening expressed as a fraction of the initial height $\left(\varepsilon_{f}\right)$ are measured. Usually, loosening in practice is performed at a soil moisture suction that is primarily determined by climatic conditions. In the laboratory experiment the unconfined compression tests were performed at $\mathrm{pF}=2, \mathrm{pF}=$ 2.7, and under air-dry conditions. The 'translation' of the quantities $\sigma_{\max }$ and $\varepsilon_{\mathrm{f}}$ into practice is still difficult, but the following indications show that there are realistic possibilities.

In scale model research with soil moving equipment, 'scaling' of soil strength was quite successful on the basis of $\sigma_{\max }$ and $\varepsilon_{\mathrm{f}}$ (Carpenter, 1969).

For a small curved blade operating in several types of soil, the kind of soil failure (shear-plane failure, steady cutting, or open crack formation) could be predicted from $\sigma_{\max }$ and $\varepsilon_{\mathrm{f}}$ (Koolen, 1973).

Loosening is usually performed by ploughing. To estimate the energy needed for ploughing from $\sigma_{\max }$ measured in the laboratory tests, use was made of 
Söhne's model (Söhne, 1956). This model calculates the draught force of 2dimensional plane blades. In applying this model it was necessary to transfer the $\sigma_{\max }$ values into cohesion values. This can be done by

$$
\text { cohesion } \mathrm{C}=\frac{\sigma_{\max }}{2 \tan \left(45^{\circ}+\varphi / 2\right)}
$$

and the assumption of the angle of internal soil friction $\varphi$ being equal to $25^{\circ}$.

\section{An implication arising from the requirements for the sample heights}

To keep the friction between the cylinder wall and soil in the uniaxial compaction test negligible, the sample height/cylinder diameter ratio should be rather small (Koolen, 1974). On the other hand, the sample height/sample diameter ratio in the unconfined compression test should be rather large, in order to keep the interfering influence of the friction between soil and plates sufficiently small. In the western world it is generally accepted that this ratio in the unconfined compression test should be $2 / 1$. To satisfy both requirements, the uniaxial compaction test and the unconfined compression test were performed as shown in Fig. 1c and $1 \mathrm{~d}$, respectively. In this uniaxial compaction test with two pistons, ratio $1 / 2 \mathrm{H} / \mathrm{D}$ is decisive for the wall friction and can be considered to be small here. When the soil sample is forced out of the cylinder after the compaction test, a sample is obtained having a height almost equal to the diameter. By performing the unconfined compression test on two such (identical) samples which were placed one on top of the other, the desired height/diameter ratio can be obtained in this test. The permissibility of performing unconfined compression tests in this way was shown from comparative experiments, the results of which are presented

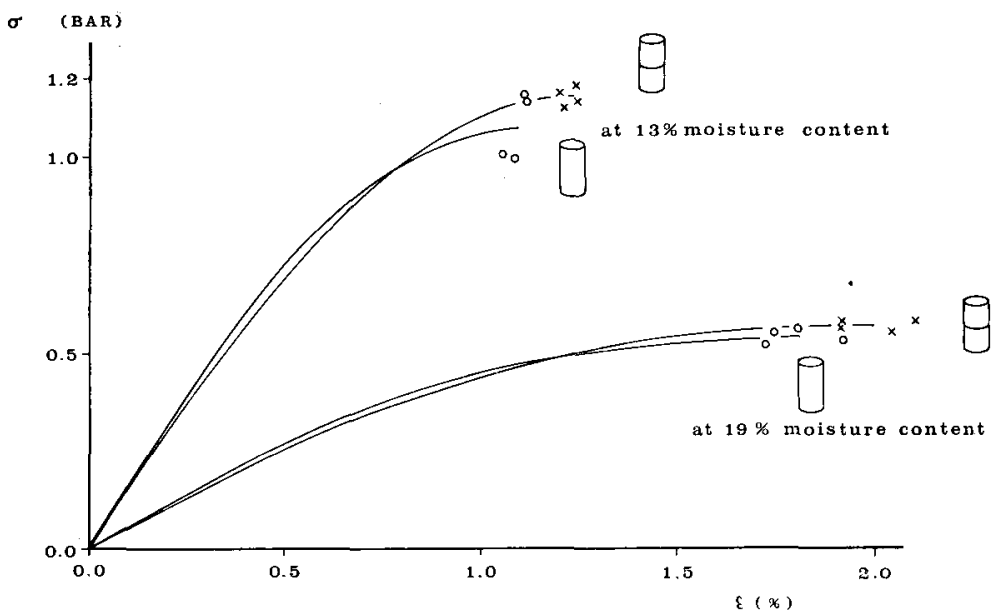

Fig. 2. Stress $(\sigma)$ - strain $(\varepsilon)$ relationships in standard and modified unconfined compression testing. (Wageningen silty clay loam, $P=49.5 \%$ ). 
in Fig. 2. (In this figure, each curve represents the average results from 4 tests. To indicate scatter, $\left(\sigma_{\max }, \varepsilon_{\mathrm{f}}\right)$ from the seperate tests are represented by small circles or crosses.) This meant that the experimental sceme had to include a number of duplicates in the pre-compaction treatment.

\section{Experimental procedure}

Aggregates in the 2-3 $\mathrm{mm}$ size class of Wageningen silty clay loam (humus content $2.3 \%, \mathrm{CaCO}_{3}$ content $3.3 \%, \mathrm{PH}_{\mathrm{KCl}} 7.4$ ) at $12.15 \%$ moisture content * (hygroscopic point $12.5 \%$ ) were poured into cylinders with an inside diameter of $50.0 \mathrm{~mm}$. The cylinders to be used for further compaction after pre-compaction each received an amount of soil containing $100 \mathrm{~g}$ dry matter. For those cylinders intended for use in unconfined compression testing after pre-compaction, the amounts of dry matter were so as to achieve a sample height of about $5 \mathrm{~cm}$ after pre-compaction. Apart from some spare cylinders, 77 cylinders were filled having the following purposes: 11 different pre-compaction moisture contents for further compaction at $\mathrm{pF} 2.7 ; 11$ pre-compaction moisture contents in duplicate for the unconfined compression tests at $\mathrm{pF} 2 ; 11$ pre-compaction moisture contents in duplicate for the unconfined compression tests at $\mathrm{pF} 2.7 ; 11$ precompaction moisture contents in duplicate for the unconfined compression tests under air-dry conditions.

After saturation in a vacuum, the samples were dried somewhat by draining off on a sand bed. Drying was continued by directing a warm heat flow through the samples. Finally, a very accurate adjustiment of the pre-compaction moisture contents took place by drying at room temperature while the samples were continually weighed. (This adjustment had to be very accurate to obtain 'true' duplicates for the unconfined compression tests: the differences in nominal precompaction moisture contents of duplicates were never greater than $0.06 \%$.) In this way the following nominal pre-compaction moisture contents were adjusted: $10,12,14,16,18,20,22,24,26,28,30 \%$. After the samples obtained in this way had had the opportunity to equilibrate for some weeks, pre-compaction was performed with an compactive stress of 4 bar.

The pre-compacted samples were saturated in a vacuum and then adjusted to the desired values of the soil moisture suction at testing ( $\mathrm{pF} 2, \mathrm{pF} 2.7$ or air-dry). Sand boxes or Kaolin boxes were used for draining off. Draining off on the Kaolin boxes lasted 6 weeks. The air-dry samples were obtained by placing the samples in a cool, dark room for 10 weeks.

Finally, the samples were tested in uniaxial compaction or in unconfined compression. The samples intended for the unconfined compression tests were only pre-compacted and not further compacted.)

The entire experiment lasted for a total of 8 months.

* In this article, all moisture contents are expressed as a percentage of dry weight.

Neth. J. agric. Sci. 26 (1978) 


\section{A. J. KOOLEN}

\section{Results and discussion}

The changes in porosity during the subsequent stages of the tests are presented in Fig. 3a. In addition to the pre-compaction effect this figure clearly shows the swelling and shrinkage effects. Porosities after shrinkage were calculated on the basis of measured sample diameters. An alternative that may simulate better practical conditions, involves a porosity calculation in which the sample diameter is set equal to the unshrunk diameter. In that case the calculated 'porosities after shrinkage' would be higher than indicated in Fig. 3a.

Fig. $3 \mathrm{~b}$ gives the changes in moisture content during the subsequent stages of the tests. This shows that the moisture content at pre-compaction has a great
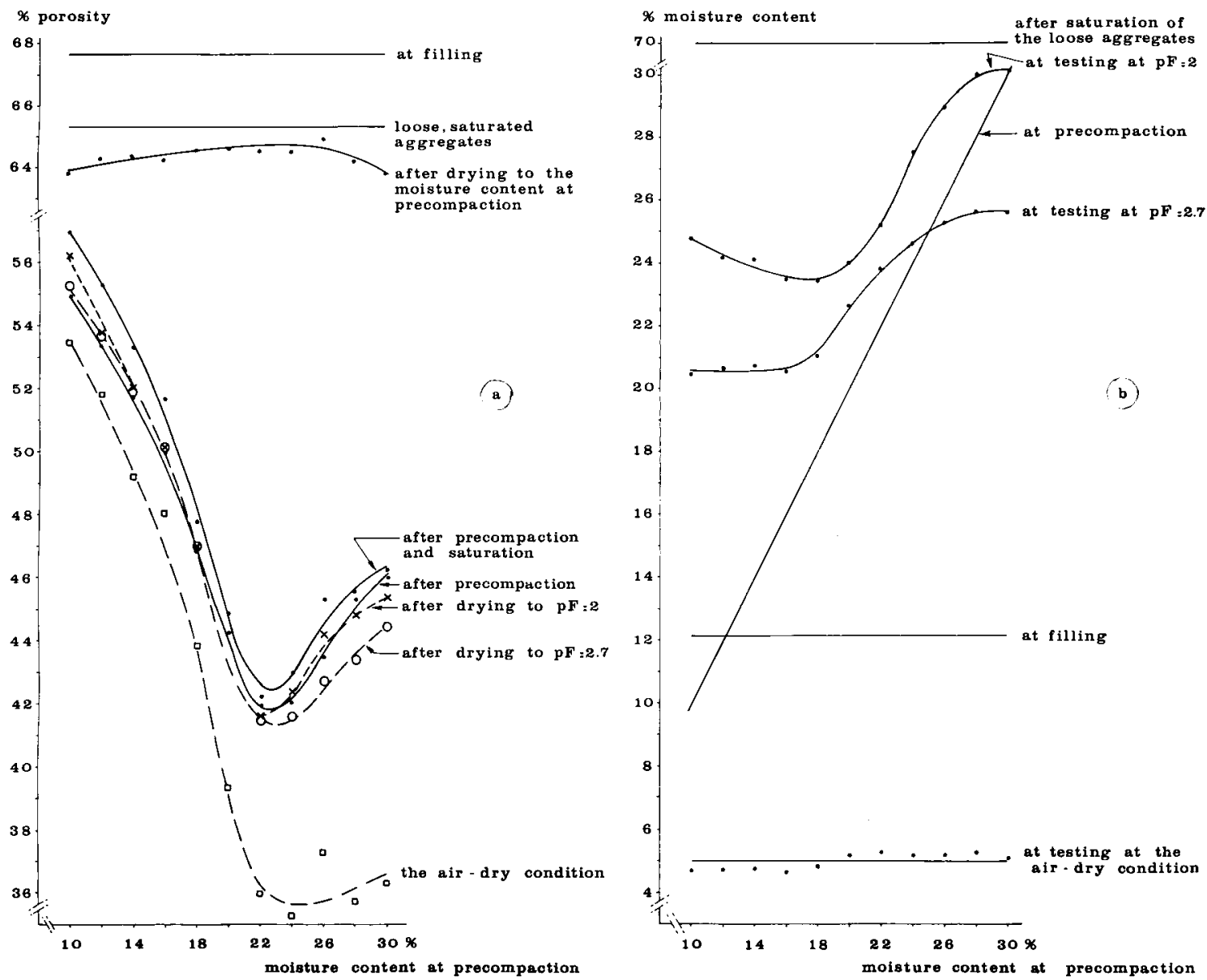

Fig. 3. Porosities (a) and moisture contents (b) at different stages of the experiment. 

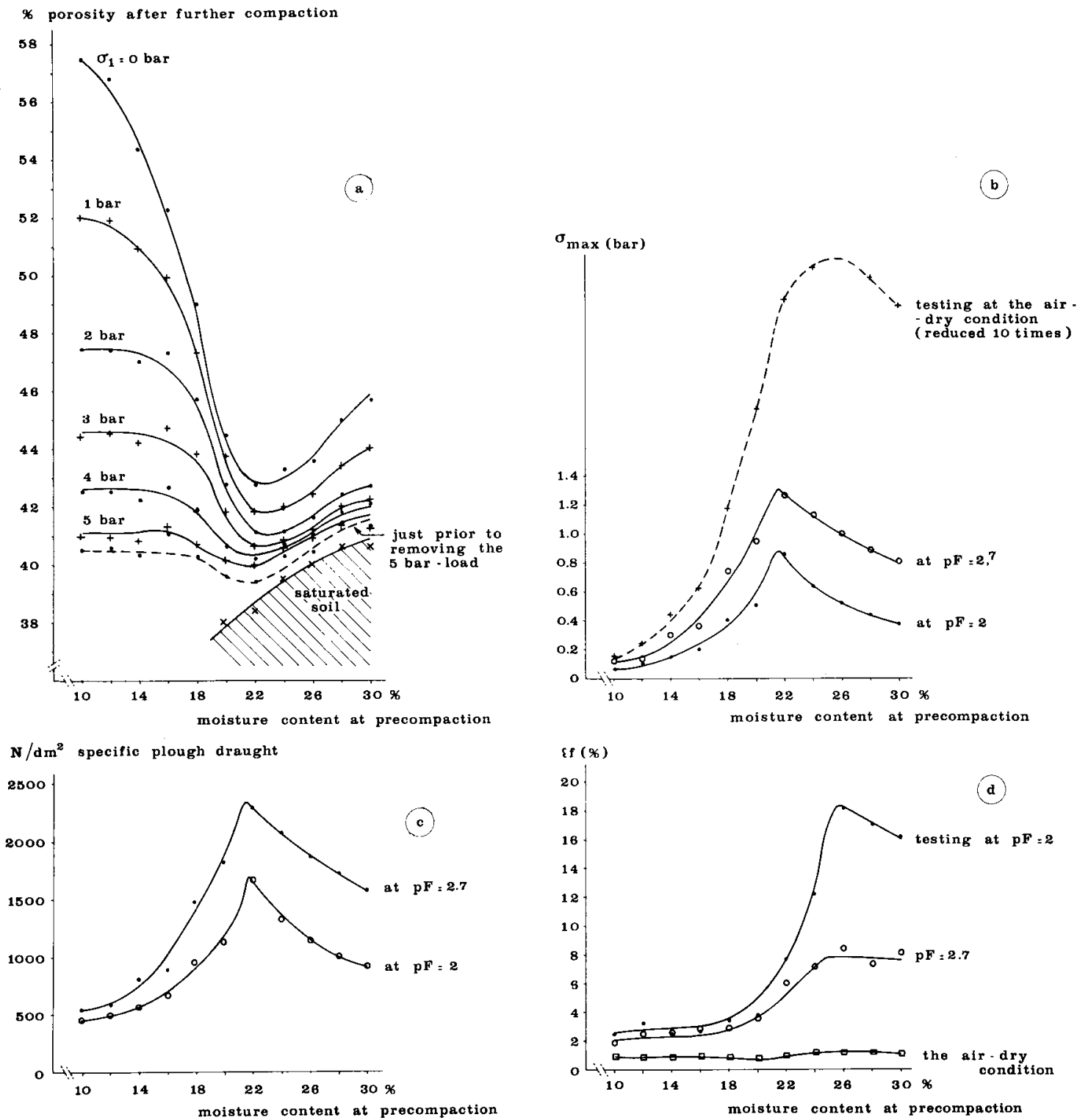

Fig. 4. Effect of moisture content at precompaction on behaviour in further compaction (a), unconfined compressive strength (b), specific draught of a tool (c), and failure strain in unconfined compression (d).

influence on the moisture content that prevails at a given soil moisture suction, i.e. on the $\mathrm{pF}$ curve.

Fig. 4a shows the effect of further compaction. Here, the sample diameters in the porosity calculations were set equal to the inside cylinder diameter. This

Neth. J. agric. Sci. 26 (1978) 
figure applies to situations after unloading and, therefore, includes elastic recoveries. The elastic recoveries were measured for the ' 5 bar' isobar. The elastic recoveries for the other isobars were estimated from the elastic recoveries for the 5 'bar'-isobar by the following formula:

elastic recovery after a load $\sigma=\frac{\sigma}{5} \mathrm{x}$ elastic recovery after a 5-bar load.

The effect of the pre-compaction moisture content on porosity does not fade out by further compaction. The shape of the isobars is, of course, determined by the moisture suction ( $\mathrm{pF} 2.7$ ) that was adjusted prior to further compaction. For this suction the sensitivity of the soil to a 5-bar compaction was expected to be highest.

Fig. $4 \mathrm{~b}$ gives $\sigma_{\max }$ from unconfined compression tests as a function of the precompaction moisture content. Fig. $4 \mathrm{c}$ was calculated from this graph with Söhne's model. Fig. 4c presents specific plough draughts for a plane, 2-dimensional blade and applies to conditions with the following specifications:

- angle of internal soil friction: $25^{\circ}$

- angle of soil-metal friction: $15^{\circ}$

- bulk density of the soil: $1500 \mathrm{~kg} / \mathrm{m}^{3}$

- cutting angle: $45^{\circ}$

- (projected) blade length $=$ blade height $=20 \mathrm{~cm}$

- working depth: $20 \mathrm{~cm}$

- low forward speed

- angle of forward failure surface: $45^{\circ}$.

Plough draughts were not calculated for the air-dry condition because the model does not give realistic values for this condition. Under practical conditions, the workability limit of the soil used is sometimes estimated as: moisture content $21 \%$. If the soil was prepared at the start of the growing season when this moisture content prevailed, and ploughed at $\mathrm{pF}=2$ after harvesting, then Fig. $4 \mathrm{c}$ predicts a specific plough draught of $140 \mathrm{kN} / \mathrm{m}^{2}$ for this ploughing. If the preparation had been delayed until the soil had dried to $20 \%$, then the predicted plough draught at $\mathrm{pF} 2$ after harvest would have been: $120 \mathrm{kN} / \mathrm{m}^{2}$, a difference therefore of $20 \mathrm{kN} / \mathrm{m}^{2}=14 \%$.

Fig. $4 \mathrm{~d}$ gives the variation of $\varepsilon_{\mathrm{f}}$. For the air-dry condition $\varepsilon_{\mathrm{f}}$ is so small that the measurement can be seriously affected by small irregularities at the surfaces of the sample ends. These undesired effects were eliminated using a formula obtained from previous measurements:

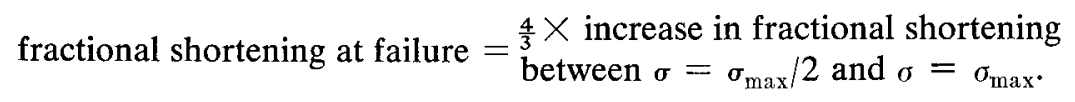

These increases in fractional shortening were measured from the recorded forcesinkage relationships, and from these measured increases, $\varepsilon_{\mathrm{f}}$ values were calculated. According to Koolen (1973) the process types that a curved blade (working depth $3 \mathrm{~cm}$, forward speed $32 \mathrm{~cm} / \mathrm{s}$ ) will cause for the $\mathrm{pF}$ condition in Fig. $4 \mathrm{~d}$, are: for all pre-compaction moisture contents the 'open crack formation 
type' will occur, but for $26 \%$ pre-compaction moisture content $\varepsilon_{\mathrm{f}}$ is so high that the boundary with 'steady cutting' is achieved. (This boundary is $\varepsilon_{\mathrm{f}}=18.5 \%$.) Consequenly, if the soil is tilled with the curved blade at a moisture content somewhat wetter than $\mathrm{pF} 2$, the 'steady cutting' process type will occur for the $26 \%$ pre-compaction moisture content.

The variations in $\sigma_{\max }$ and $\varepsilon_{\mathrm{f}}$ cannot be fully explained by variations in moisture content and porosity. Variations in other soil physical properties also play a role. More information on this phenomenon has been provided in (Koolen, 1976b).

\section{Conclusion}

This article describes a laboratory experiment with small samples, in which the influence of a soil tillage process on subsequent tillage processes was studied. Attempts to translate the results into practice were also made. The translation is still difficult, but the fact that this laboratory experiment requiring a high accuracy appeared to be feasible, is a stimulus for developing further 'translation' possibilities.

It seems desirable to combine laboratory experiments with field experiments: the laboratory experiments allow the testing of many different conditions, as the field experiments take care of an adequate translation into conditions found in practice.

In describing the above method, the mechanical aspects of tillage processes have been emphasized. It should be noted that soil physical aspects can also be studied adequately with this method.

\section{References}

Anonymous, 1973. Landbouwbanden. Ministerie van Landbouw en Visserij, Vlugschrift voor de Landbouw No 204. IMAG, Wageningen.

Carpenter, T. G., 1969. Utilization of artificial soils for earthmoving model studies. Ph. D. Thesis, Mississippi State University, Starkville, Miss.

Koolen, A. J., 1973. Failure patterns in different soils produced by a curved blade with a small angle of approach. Proc. Subject Day on the mechanical behaviour of agricultural soil. Rep. natn. Inst, agric. Engng, Silsoe No 7.

Koolen, A. J., 1974. A method for soil compactibility determination. J. agric. Engng Res. 19: 271-278.

Koolen, A. J., 1976a. De invloed van de mechanisatie op de bodemstructuur, belicht vanuit de gronddynamica. 100 Jaar onderwijs, voorlichting en onderzoek in de Landbouw. Contactdagen 10 en 11 maart 1976, Wageningen.

Koolen, A. J., 1976b. Mechanical properties of precompacted soil as affected by the moisture content at precompaction. Proceedings of the 7th conference of the ISTRO. Rep. Div. Soil Mgmt, Dep. Soil Sci., Agric. Univ., Uppsala, Sweden No 45.

Söhne, W., 1956. Grundlagen für eine landtechnische Bodenmechanik. Grundl. Landtechnik, Heft 7 . 